\title{
The perils of confusing lifelong learning with lifelong education
}

\author{
Stephen Billett \\ Griffith University, Australia
}

Lifelong learning is a socio-personal process and a personal fact. As such, it is conceptually distinct from an educational provision that constitutes an institutional fact. In building on this distinction, this article seeks to elaborate a central flaw in the precepts for, conceptualisation of and enactment of the report 'Learning through life', thereby proposing it as being ill informed, partial and of limited use. Moreover, it is potentially perilous to the project of lifelong learning as it could well lead to the misrepresentation, marginalisation and undermining of a broadly premised provision of support for adults' learning. The emphasis on educational provisions rather than individuals' learning and ignoring of the diversity of settings in which individuals' learn, stands as major flaws, seemingly arising from the authors' perspectives and stakeholder interests. Largely neglected throughout is the scholarship on adult learning and development across the life course. Instead, miscellaneous and often unhelpful sources inform the report. The overall recommendations reflect a view of human development that was abandoned decades ago as being unhelpful, and whose rejection is more now pertinent than ever. Moreover, it largely rehearses a tired educational discourse and unquestioningly privileges the value of taught courses, ignoring the importance and ubiquity of learning experiences outside of courses that are the most common source of learning across individual's lives. Within its discussion and the shaping of its recommendations, lifelong learning is presented as an institutional fact rather than a personal process. That is, erroneously, learning is claimed to be a product of what social institutions enact rather than being something done by people. In doing so, a misinformed and inaccurate account of lifelong learning emerges and a narrow conception of how that learning might best be promoted and supported is advanced. Yet, the great peril within this document is in promoting a form of learning support that lends itself more to management of educational provisions than concerns about individuals' learning. The peril here is that other circumstances and settings in which learning occurs stand to be ignored or further marginalised. In all, not only is this report an opportunity lost, it represents a significant threat to an important and viable field of human and societal development across the life course: lifelong learning.

\section{Lifelong learning as a socio-personal process}

Learning is something that people do, and all the time. It requires consciousness and the capacity to utilise what we know and leads to change both in what we know and how we know. Indeed, it is our ability to be reflective and to share what we have learned with others and across generations that is central to our existence and continuity as a species (Taylor 1985). Hence, for both individual development and societal progression we need to learn both knowledge that is new to us, but others might know, and develop further what we know (Billett 2009). Moreover, learning is something that humans do continuously and across our lives: we are all and have to be lifelong learners to cope with new and familiar experiences. Also, learning is not something wholly that is dependent upon others. In the absence of social partners and forms, we would still continue to learn. The need for continuous learning includes completing tasks required simply to live, there alone enjoy connected, effective and worthwhile lives. So, this learning is directed by our individual needs and intentionality that are mediated by our capacities and interests, and shaped by personal imperatives albeit enriched continually by contributions that are external to us in the social and brute world beyond us. Learning is, therefore, very much a personal process directed by our capacities, interests, situations, and support, and it arises through engaging the human mind and consciousness. Hence, this learning is not wholly dependent on external sources, particularly those that promote particular kinds of learning through schools, universities, colleges, workplaces etc. Instead, it occurs all the time as we humans engage in activities and interactions including those with social partners in our homes, with our families, friends and acquaintances, in our work, in our workplaces, in our 
community engagements: in the everyday tasks in which we engage, and when we are alone. For those participating in them, learning also arises through educational programs (e.g. courses), and sometimes that learning is what teacher or the institutions intend. Yet, the learning of rich (i.e. adaptable) knowledge is not necessarily privileged by experiences in educational programs as it also arises through practice experiences (Scribner 1984; Raizen 1989; Ericsson and Lehmann 1996).

There are a range of purposes to which individuals engage in and direct their learning, and with different degrees of interest, engagement, intentionality and effort. These purposes include learning to communicate with others, engage with social partners, and developing the capacities to engage in socially-valued activities, an important one for most adults is their paid work, for instance. These purposes include continuing to develop occupational capacities across working life including learning how to engage in new occupational requirements. There is also learning associated with roles that emerge across our lives, to be a son or daughter, brother, sister, twin, partner, parent and carer for parents etc. Both the processes of and outcomes of this learning are deemed by individuals and/or others as being either effective or less than effective for these roles, and also worthy of effortful engagement. This is particularly the case for learning that is personally transformative (Perkins, Jay et al. 1993; Tobias 1994; Allan 2005). Likely, when learning new knowledge, as well as being effortful, the process of meaning making also involves monitoring and self-regulation, as well as personal agency (Rohrkemper 1989; Cavanagh 2008). Hence, both the purposes and process of learning are personal facts; something that humans do and shaped by personal factors. Indeed, it is difficult to find an informed account of human learning that does not position the individual and their consciousness, subjectivity and/or intentionality as being centrally in directing the purposes and processes of what they experience and learn. Behaviouralist accounts may be the exception here. However, most other accounts in different ways by different degree emphasise the importance of humans as active meaning makers who do much to shape the direction and intensity of the learning processes. The key difference amongst various accounts of human learning and development is often the degree by which that learning is also shaped by the world beyond the individual, but with which they engage.

Indeed, beyond individuals' contributions much of the purposes for effective human learning can be attributed to the kinds of purposes that are to be achieved, guidance and support that are found in outside of the individual. The vast majority of our purposes, even when performing solitary activities, are socially shaped (Scribner 1990): they are institutional facts: the product of society (Searle 1995). Also, much of the guidance and support arising from engaging with other people, either directly (Rogoff 1995) or indirectly through observing them, listening to them (Billett 2001), undertaking the activities they suggest (Pelissier 1991), reading what they have written (Rogoff 1990) or engaging with what they have produced. These kinds of engagements and activities are important because much of the knowledge that we need to fulfil our roles and direct our energies towards are derived from the social world (Scribner 1985; Rogoff 1990; Billett 1998). Hence, we need social partners to engage with to access socially-derived knowledge. So, throughout our lives, our learning is supported by parents, siblings, friends, family members, associates at school, work, in community activities as well as those who role it is to help us learn (e.g. teachers, trainers, mentors). In all, lifelong learning is a socio-personal process as we negotiate our thinking, acting and doing across activities and interactions. These contributions comprise a range of institutional facts (i.e. those created and enacted by society) (Searle 1995).

However, in an era of universal compulsory education and high participation in tertiary education in most developed countries, it is often incorrectly assumed that the learning arising from activities and interactions in educational institutions is in some way privileged or constitutes the major and most legitimate contribution to our learning. Yet, there is little evidence to support the first assertion and the latter most likely to apply to those whose experiences are dominated by those settings (i.e. school age children), and even then only partially. Instead, there are a range of contributions that support individuals' lifelong learning and do so quite effectively. This is not to deny or downgrade the contributions of experiences in educational institutions or the efforts and activities of teachers, trainers and mentors, which are often invaluable and sometimes 
indispensable. Indeed, well-organised and engaging experiences are likely to make rich contributions to learning, as can engaging with more expert counterparts. However, it is important to be reminded, that the range of experiences and activities occurring outside of educational programs, and that many of our requirements for effective lifelong learning cannot be realised through educational provisions, or even direct teaching. That is, there is much knowledge across human life is learnt and not taught. Moreover, it is not possible or desirable that lifelong learning is dependent on access to educational provisions, because learning of necessity, both in the form of new learning for individuals and refining what is known, most typically arises through everyday experience (Billett 2009).

This process of lifelong learning is worthy of being carefully considered and comprehensively understood because of its salience to individuals, their families, communities, work and workplaces. When we learn, we not only develop capacities to fulfil our societal and economic roles, but we also engage in remaking and transforming those social and economic activities (Billett, Smith et al. 2005). Consequently, lifelong learning is essential not only to ourselves and those close to us, but also the remaking and transformation of the society in which we live (Giddens 1991). However, given the importance of this learning and the remaking of sociallyderived norms and practices to the continuity of our workplaces and communities, it is not surprising that others become interested in seeking to organise and direct these processes and realise particular outcomes through our learning. Principally, national governments and global agencies have long sought to direct and support learning for particular purposes. The introduction of mass compulsory education and the provision of vocational education were as much about attempts to direct citizens' interests and energies towards desired social and economic goals, that merely have a more broadly educated population (Gonon 2009). Hence, powerful institutions have been developed for the purposes of directing individuals' learning in particular ways (i.e. bureaucracies, educational sectors, national and international agencies) with their goals, norms and practices, and discourses that seek to direct, promote, support And secure particular kinds of learning across individuals' lives. As we know, very few educational institutions were founded by individual or groups of educators (Skilbeck 1984). Instead, it has been the state, social groupings or religious institutions that have established and sustained educational institutions, and ordered the kinds of intended outcomes for participants and the kinds of experiences that will be provided to achieve these outcomes. For instance, many definitions of curriculum emphasise achieving the purposes of the school (Glatthorn 1987; Marsh and Willis 1995).

Yet, there has, and always will be, tensions arising between the kinds of provisions that aimed to promote and support particular kinds of learning, and the interests and intentionalities of those who learn This is captured in conceptions of curriculum that emphasise distinction between curriculum as intents, something enacted and also what individuals' experience and learn. These tensions are most likely to be the strongest when key institutions intensify their efforts to control and regulate individuals' learning, in ways in which is inconsistent with their needs (e.g. Mealyea 1985) or interests (e.g. Hodges 1998). This intensification of effort is most likely to occur during periods of social or economic uncertainty (e.g. Stenhouse 1975; Stevenson 1992). Habitually, this circumstance leads governments and others to reassert the importance of fundamentals (e.g. back to basics) in compulsory education, and a stronger regulation and control of post-compulsory education. The widespread use of competency based training, industry standards, national core curriculum, have become commonplace within the vocational education as government seeks to align what is learnt by students directly with the requirements of industry. While this attempt to regulate and control individuals' learning may appear to be rational from governmental and economic perspectives, it may not always be well aligned with others' purposes and interests (Jackson 1993). Often, the focus on content of courses does not meet the needs of those who they are intended to assist. For instance, those who own or work in small businesses often claim that their needs and concerns not met within nationally curriculum provisions that reflect the form and interests of large enterprises, not small ones (Coopers and Lybrand 1995). In these ways, efforts by 
government and key agencies in seeking to control and regulate individuals' learning and for particular purposes may not always be doing so in ways that achieve their own goals.

Moreover, the interest of key agencies can do much to change the language, or discourse of how this learning is conceptualised, and should be progressed and for what purposes. Many governments have adopted a particular view of what constitutes competency, which is usually highly measurable and behavioural in form. This then comes to constitute the bases upon which the requirements for educational arrangements aimed to prepare competent workers, regardless of whether such measures are indeed the best curriculum intents for the organisation, teaching and assessment of learning for occupations. Moreover, the espoused purposes of learning throughout our lives can be reshaped and re-privileged in particular ways by such key agencies. For instance, as a result of the OECD's year of lifelong learning in 1996, the key focus for this learning is now seen as being primarily about achieving economic purposes, and in which, individuals have to take a key role (Organisation of Economic Cooperation and Development 2000). Prior to this event, the economic emphasis was most evident in their claims for vocational education, albeit as a system primarily involved in initial occupational preparation. So, there are, on the one hand, individual and personal purposes and processes (i.e. personal facts) that constitute lifelong learning that are as necessary as they are important for individuals, their communities, countries and humankind. Then, on the other hand, are the educational purposes for and contributions to that learning from the world in which individuals inhabit, and engage in activities and interactions (i.e. institutional facts). Often, and as noted, these educational purposes reflect the interests of others, rather than those who are positioned as learners. Yet, it is the balance and reconciliation amongst the needs and the imperatives communities, workplaces and country and, perhaps most importantly, individuals themselves that is central to considerations of what constitutes the purposes, assesses and outcomes of individuals' lifelong learning. However, in considering this reconciliation it is helpful to rehearse the opening proposition, that it is individuals who learn, and do so constantly, and that this learning is ultimately shaped by their needs, interests and capacities. Indeed, Foucault suggests that no amount of regulation, control and surveillance (i.e. institutional facts) can change people in ways that they do not want to. For instance, in the Care of the self: The history of sexuality volume 3 (Foucault 1986) he claims that even extreme social press or regulation can control desire (i.e. personal fact). Consequently, arrangements that seek to explain, order, organise and shape that learning in particular ways need to fully account for these conditions, and principally account for and accommodate personal facts, such as interest and desire that shape human intentionality and effortfullness in the process of learning.

This long preamble offers a view of and framework for lifelong learning that arises from informed enquiry and diverse sources of theorising into human learning and development. The available literature is extensive and, its considerations are not constrained by institutional imperatives, such as those that seek to primarily understand learning as arising through participation in taught courses offered by schools, vocational education and higher education or other institutions. Removed from orthodoxies that privilege and emphasise what are the purposes of, what occurs in and what is held to be legitimated by experiences in educational institutions, much of that work has provided nuanced and accounts of lifelong learning. These accounts are those that explain learning through working life, in community activity, in consideration of age or disability. They are articulated in specialist journals such as the Studies in Continuing Education, Studies in the Education of Adults, the International Journal of Lifelong Education, Journal of Workplace Learning, Vocations and Learning: Studies in professional and vocational education and others. It is through such a preamble and such a framework that the processes and outcomes of the Inquiry into the Future of Lifelong Learning are appraised here and found to be wanting. Moreover, the report of this inquiry - Learning through life - is seen as a missed and wasted opportunity, that misconceptualises lifelong learning, perhaps intentionally, and perilously, and seeks to position it in a narrow, linear, restricted, and ultimately, unhelpful way: as courses to be organised, enacted and regulated. It seemingly seeks to position lifelong learning as something to be organised for specific 
institutional purposes, and in ways that have been deemed unhelpful and even counter productive elsewhere.

\section{Lifelong learning or education}

The problems outlined in and aimed to be addressed through the Inquiry into the Future of Lifelong Learning as advanced through its report are undoubtedly worthwhile and important. Given global concerns about lifelong employability, the lengthening of working lives and the realisations that ongoing development across working lives is necessitated by the dynamic nature of the knowledge required for work, and engagement with others and in socially-derived activities, the promotion and support for adults' learning across their life span is now essential for achieving key economic and social goals, as outlined above. Indeed, the aging populations in most countries with advanced and developing economies make this ongoing learning a global concern as the capacity to sustain economic competitiveness and the social requirements of that population are dependent upon the learning by this cohort. Britain is far from immune from these concerns and issues. As the report identifies, there are many people in Britain who would benefit from enhanced opportunities for their learning, including enhanced participation in educational programs. It has proposed that this participation in courses can assist the development of capacities that would permit these individuals to engage more fully in societal and economic activities. This premise may well be correct, partially at least. Those identified in need of this provision include those individuals seeking to participate more fully in working life, those who are disengaged from society, are incarcerated, unemployed, or unwell. This listing extends to whose wanting to secure transitions from their current circumstances to other or more productive ones, including those who are marginalised. So, there are a range of important focuses and goals for the promotion and support of adult learning across the life course. The salience of these imperatives makes the purposes of this inquiry worthwhile, its deliberations worthy of analysis and its outcomes needing to be scrutinised.

Moreover, a national inquiry into the field of adult learning (i.e. provisions for, across and beyond working life) offers the promise of more fulsome understandings of the field and its potential and current contributions. Again, this is an important goal because the broad field of lifelong learning and the settings in which it occurs is not always fully understood or appreciated, particularly by those in other educational fields, who often see teaching and learning as being synonymous, as do seemingly the report's authors. All of these needs likely arise because the field of adult learning does not have the kinds and level of institutional support enjoyed by schooling, vocational and higher education. This circumstance is likely and partly a product of the interests in and provision for adults' learning being widely dispersed and in situations where the intentional provision of support for this learning is not always the explicit key priority (e.g. workplaces). Indeed, because the provisions of lifelong learning experiences and support for learning extend well beyond those offered by educational institutions, there is much to be done for these forms of learning support to more fully acknowledged, and the learning arising from them being recognised and certified through worthwhile and esteemed processes. Hence, this provision may need greater coherence and greater legitimisation, yet in ways that honour rather than violate its existing practices and strengths, which would have been a useful recommendation from this report. Essentially, this broadly distributed provision warrants greater legitimisation because it is does not enjoy the same status as other sectors and perhaps more adequate resourcing, given its potential. Yet, this fact is largely ignored in this report.

Hence, the opportunity provided by this inquiry to appraise, legitimate and extend the range of activities both within and outside of educational institutions is most welcomed. However, such an inquiry also brings the threat of unhelpful meddling, and risks of its recommendations being shaped by mis or uninformed accounts. For instance, education sectors have been adversely affected by the latter kind of accounts. These circumstances have arisen when interests from those outside of educational sectors anticipate reforms premised on their assumptions and needs. These kinds of assumptions are often practiced quite un-reflexively, because whilst accusing educators of not understanding the needs of business, those from business see little need for their decisions to be 
informed by an understanding of educational or learning processes (Billett 2004). The outcomes of these kinds of inquiries are usually less than satisfactory, and because of their lack of understanding make recommendations that are impossible to implement (e.g. generic skill development). Moreover, when the anticipated changes fail to be realised it is rarely seen as a failing of the recommendations or their sponsors, just the ineptness of those who administer and teach in educational institutions. This circumstance usually prompts fresh inquiries and more direct interventions, which of necessity have to exclude those who are so inept that they failed to implement effectively the previous inquiry's recommendations.

Yet, in this report is a curious rehearsal of ill-informed and specific stakeholder perspectives. That is, the project of promoting and supporting adults' lifelong learning and recommendation is cast through an educational institutional perspective that throughout uses an emphasis on practices and processes from educational institutions and program, rather than one focussed on learning, thereby misrepresenting lifelong learning and narrowing its purview and responses. Essentially, education and learning have been conflated by those who seem to privilege the former and misunderstand the latter. The terms used to consider the key issues, the processes discussed and recommendations elaborated all privilege an educational discourse. Early in the report it is claimed that the learning and education are essentially the same (i.e. consonant concepts), despite the former being a personal fact and the latter an institutional fact. The discussion and focus within the report is framed by an educational discourse including the practices, priorities and norms of educational institutions, again, all institutional facts. Frequently mentioned across the report are issues of courses, qualifications, courses, participation, courses, courses and more courses. Yet, in doing so, what constitutes some of the most salient, enduring and significant contributions to adults' learning throughout life (i.e. those occurring outside of courses) are not even considered, presumably because they do not sit easily within an educational discourse. The kinds of practices that are likely to be inclusive of that learning and many, perhaps the vast majority of learners remain unaccounted for. A tempting solution to these central failings is to simply rename the report as Education throughout life. This would far more accurately represent the focus of and discussion within the report, because it is largely about education not learning. Yet, while more accurately capturing what is privileged in this report, the changing of titles would fail to do justice to the important field of adult development, what that means for the kinds of adults who are identified as being marginalised and for achieving a viable, effective, broadly positioned and highly esteemed provision of adult learning.

Consequently, it is necessary to engage with this report and suggest how a framework for lifelong learning, such as that outlined in the introduction, is not well represented across its pages and recommendations. This includes consideration of the report's purposes, its emphasis on courses and the need for a more broadly positioned framework for lifelong learning.

\section{Misaligned focus and purposes}

There is clearly an intention to address a range of pertinent issues and needs in this report. Most of those referred to are aligned with issues arising from the detachment and/or disengagement of adults from institutional forms of engagement (e.g. work, educational provisions), although some refer to educational provisions and consider ways in which this disengagement can be reversed. So, there are clear intents that guide the deliberations within this report and they are largely about educational provisions. Yet, there is a real misalignment between the focus and contents of this report and its stated purpose. It claims to be about understanding and promoting lifelong learning, when it is really about lifelong education. A consistent response to compounded and entrenched problems articulated across this report is that these problems are addressable through participation in courses. Yet, scant attention is given to the evidence that points to the limitations of this solution, particularly for other processes and sites where most of individuals' and particularly, adults' learning occurs. Where is the accounting in this report for the contributions of other settings through which the vast majority of learning across working life occurs? Take workplaces, for instance, the learning arising through experiences in these settings not only can secure outcomes required for the 
particular workplace, but also those that are central to the development of occupational competence that is applicable more widely, and the capacities for working life that are supra-occupational. Moreover, these and other kinds of settings might be better placed to secure the desired kinds learning outcomes of those who are excluded or disengaged from them.

It is such a misalignment intentional or unintentional? It is hard to discern. The claim that education and learning are either synonymous or easily reconcilable concepts is advanced early in the report (p.9). Statements are made that concepts mean different things to different people that they are used here as synonyms. Yet, immediately after the statement, discussion returns to concepts and practices which are primarily about educational provisions and not a consideration of learning. However, in attempting to make these concepts synonymous, the problem of how to represent something that is primarily a personal fact, as an institutional fact is never engaged or satisfactorily explored. What is claimed that the approach used in the report 'realises breadth with manageability' (p.9), without articulating what this means. However, the device used is simply to ignore the former (breadth) and offers a narrow perspective of lifelong learning (i.e. that which arises through courses). Indeed, commencing early and then elaborated throughout is the idea that lifelong learning only occurs through teaching or participation in courses (i.e. an institutional fact). This initial misconception undercuts the worth of not only the relevance and usefulness of the document as an account of lifelong learning, but also its explicit focus: education provisions across life. This is because, as a starting point, a consideration of educational provisions across life, should it least be in part and perhaps largely informed by processes of learning and individuals' roles in that learning. This oversight is particularly disappointing in the context of lifelong education and lifelong learning. Elsewhere in discussions about the learning of young people, people learning for their preferred occupations or other interests the emphasis on the educational process and educational institutions is always strong. Here, all too often, the concept of learning is subsumed within the goals and purposes of the educational provision, and often the institution itself. It seems that in giving control of this inquiry to those whose expertise and focus is primarily about educational institutions that a curious rehearsal of stakeholder interest is enacted. That is, as with industry representatives ignorantly advising about education, those with expertise in educational institutions are advising on something outside of their expertise.

As discussed above, initially conceded in this report and accepted widely elsewhere and, learning is a very distinct process from educational processes and provisions. It is an ongoing and continuous process in which all humans engage as they think and act. Consequently, discussions suggesting that individuals may or may not learn in particular situations - "The good news is that millions of people across the UK take part in learning of one form or another" (p.60) is nonsense because everybody learns all the time. Then, there are tables indicating how learning is differentiated across individuals dependent on the occupations and class (p. 66), and that it is possible to identify the percentage of time in which they learn (i.e. in a course) (p. 101) is uninformed as are the gendered differences in the processes of learning (p. 70) seems inconsistent with what is proposed early in the report. These statements indicate that the authors misunderstand the very processes on which they are advising.

So whose advice was sought in attempting to reconcile concepts that most informed commentators would see as being distinct? There is reference the issue of learning from Wikipedia, novelists are consulted, "Educating Rita' is consoling, and the Bible, Churchill, Shakespeare used authoratively and even Monty Python provides advice. But other and more credible voices are absent. Where are the perspectives of the many theorists who have advanced our understanding of the process of learning and who offer particular perspectives on that process and whose advice will be particularly needed in dealing with some of the more intractable problems identified in the report? Why is there an absence of references from the journals listed above, consultations with the authors of those articles and those who research in this field? An entire Teaching and Learning Research Program was dedicated to these ends, yet seems not engaged with by authors of this report, who propose the need to engage with researchers ( $p$ 32). This extensive program of publicly funded research and undertaken by some of the most informed, experienced and adept researchers 
in the English-speaking world addresses issues around lifelong learning. Yet, their contributions and that significant investment by British taxpayers appear to be ignored by those who prepared this report. Almost absent are those researchers and their contributions are rendered invisible. So, it is perhaps not surprising that focus of the report is misaligned with its purposes (lifelong learning), by most informed accounts, and that this is likely to be to the detriment of the field of human activity referred to as lifelong learning, its support and acknowledgement. This threat is perhaps no more evident that through the emphasis on courses as a basis to understand lifelong learning and a solution to issues of human engagement and development.

\section{Courses, courses, courses and more courses}

While claiming to be advancing a broad view, a report which aims to inform the future of lifelong learning is weakened considerably by narrowly positioning learning as primarily something which arises through individuals' participation in educational provisions (i.e. courses). Across the report vignettes are provided, some that are proudly stated as being fictitious. Yet, they nearly all focus on educational provisions (p.22-23, p.25, p.29-30, p.32, p.42), and there is also reference to a romantic comedy about returning to education as taught courses on page 27. Moreover, its advice is quite limited in both the general sense of its suggestions and, particularly, limited in responding to some of the key issues of older, disadvantaged, incarcerated and other kinds of learners. Absent here are references to learning through practice, or through community-based or interpersonal means that are commonly proposed for individuals engaging in transformative learning. Nor are there innovative models of learning support for those who are disillusioned with educational provisions. Instead, there is a single solution: courses, courses, courses and more courses. It seems particularly odd that in considering the importance of assisting older citizens, those who are disadvantaged, those who were incarcerated that the issues of their sense of self and subjectivity appeared to have been ignored. These folk just have to go and do a course. There is little commentary about the degree by which those targeted will be interested in and have the readiness and capacities to participate in courses. Yet, seemingly forgotten here is that educational provisions are nothing more or less than an opportunity for individuals to engage in and change. How individuals elect and are ready to engage is as important as an organised educational provision. Yet, by commencing with a focus on educational provisions and principally those enacted through courses, not only is an understanding of learning neglected and rendered posterior to educational provisions, the very bases by which the educational goals that are aimed to be achieved are unlikely to be realised. More to this, the report suggests a systems approach is required, yet without a clear view about the purposes, focuses, and prospects for such systems to address the issues which it claims are important.

However, in offering a systems approach to meet the needs of learners across the lifespan, it is suggested that there has been a return to models that have been shown to be unhelpful. The framework proposing an age-related scheme for organising learning support ignores criticism of earlier models such as Erikson's account of development across the life course (Erikson 1959). Yet, contemporary life is not about a linear progression through societally-ordered stages that were purportedly identified in middle America in the 1950s. Instead, people need to change occupations, and forms of employment, experience redundancy and periods of unemployment at different point in their life histories, and divorce, relocation, caring for wayward parents and children. So, in place of a system based on categorises of age, and attempts to characterise needs at particular age stages, more helpfully is there to have and organise arrangements experiences and interactions of particular kinds focussing on:

i) initial preparation for occupational and societal roles,

ii) transitions across social and economic roles,

iii) management of disappointment in social and work life,

iv) revitalisation (e.g. professional development) and

v) bases for overcoming bias, albeit gender, ages or racial. 
Except for the very youngest and oldest, a response in the form of an age-based categorisation of learner needs ignores the limitations of simple stage development theories, and offers an account of development as a linear progression with predictable needs at particular needs.

\section{The importance of framing lifelong learning}

On page 19, readers are asked to consider whether the report: i) offers solutions that are ' lifelong' and 'lifewide', ii) has addressed the full range of learning experiences, iii) proposals will increase learners' and citizens' autonomy, iv) accounts for social justice, v) sufficiently acknowledges difference, and vi) sets out the necessary infrastructure for lifelong learning? The first five questions stand as being worthwhile and important for framing lifelong learning, while the last is more questionable, as it privileges institutional facts. Given what has been proposed above, it is not surprising that negative responses are recorded against each of these questions.

It is quite likely that, however, all of the critique above will be easily dismissed, probably by the authors, as a quibble about distinctions between learning and education. Indeed, the critique offered here could be dismissed here as academic nit-picking, territorial turf wars, or self interest ("he researches learning through work doesn't he") and would be very unimportant except for five distinct considerations that suggest the limitations of this report need to be articulated and redressed in any enacting of its recommendations.

Firstly, a provision of lifelong education should be premised upon a consideration of individuals' learning, in all its complexities, contributing factors individual differences etc, including the circumstances associated with how that learning progresses. Therefore, by only focusing on and having a starting point as a provision of lifelong education, lifelong learning is misrepresented and misinformed, and skewed. In the vignettes provided throughout this report there is a constant reference to education provisions, particularly courses and the like. These are then set up to be aligned with the recommendations. Absent here are considerations of the very bases by which even an educational provision should be considered and conceptualised. The premises for a lifelong learning pedagogy and curriculum are not developed or elaborated, nor the role of individuals' personal epistemologies in all of its deliberations. A frame work for lifelong learning, importantly, needs to account for the kinds of considerations advanced in the opening section.

Secondly, rather than achieving breadth, the very narrow instances of learning settings and support discussed here limits the purchase of this report. Certainly, these courses are provided in a range of settings and by a range of institutions, but the examples are quite restricted to the provision of courses. Where are the references to learning how to negotiate changing life expectations and demands, of becoming a parent, caring for elderly parents, managing financial matters in an era in which individuals are held to be responsible for their own post-retirement income, making informed decisions about health care, purchases, and the balance between work and other forms of daily commitments? These kinds of learning, which are probably the most common and enduring, are unlikely to be the focus of courses and not likely learnt through courses except when particular initiatives come along or key turmoils press individuals to participate. However, the most common sites and settings for learning that which occurs throughout everyday thinking and acting largely sit outside courses.

Thirdly, in recent years the United Kingdom government has expended generously in the area of research into learning through work and other forms of everyday practice. An entire TLRP program was dedicated to these ends. This program engaged some of the most informed, experienced British researchers to address issues around lifelong learning. Yet, their contributions and that investment seem to be ignored by those who prepared this report. Almost absent are those researchers and their contributions are invisible. Yet, it is the kinds of insights, perspectives and findings provided by this program of research that can inform a comprehensive framing of a project that seeks to enhance the lifelong experiences and outcomes for the British population and, in particularly, those who are disengaged and disadvantaged. Instead, they drew on Wikipedia and popular culture. 
Fourthly, the misaligned focus of this report and its narrowness together squander the opportunity provided by a national inquiry into adult learning. Where are the considerations of how learning through working life can best be promoted? The suggestions for how workplaces might seek to support the learning for lifelong employability, what provisions should be available, and what worker as learners should be doing. Where are the recommendations how the recognition and certification of learning that occurs in British workplaces, what needs to be dome to overcome employer age bias that is purportedly restricting the opportunities for workers aged over 45? This narrowness then limits the framing of what constitutes legitimate lifelong learning experiences.

Fifthly, against claims of seeking to balance breadth with manageability, the former has been negated and the latter emphasised. The sense is of a report with a pre-destined outcome, something established before hand and this report merely working towards that end, using pop and conversation style in place of rigour, being inclusive and reflective. Hence, there is a real threat that a consideration for administration and regulation of experiences may well come to emphasised in policy deliberations arising from this report.

It follows from this discuss then that, a framework for lifelong learning needs to be inclusive of the entire scope of purposes and experiences that shape the personal fact of ongoing learning. These intents and these circumstances can then be considered in terms of their effectiveness, completeness, and how they might be improved. In particular, consideration might be given to what kinds of experiences can likely achieve particular learning goals, and were these experiences might be best located and enacted. Part of this consideration is also how best government imperatives associated with inclusivity, continuity of development and the maintenance of lifelong employability can best be realised for individuals. Such a framework might also be premised upon the kinds of goals and transitions that individuals will need to secure or in their lifelong learning project. So, rather than a system of support for learning being premised on categorises of age, other and more inclusive kinds of categories might be far more useful. As foreshadowed, these categories might include focussing on initial preparation for occupational and societal roles, transitions across roles, management of disappointment, revitalisation and bases for overcoming bias, albeit gender, ages or racial. In all, the development of such a framework might be premised on direct engagement with these individuals, not in fictitious stories about them.

\section{References}

Allan, J. K. (2005). "Farmers as learners: Evolving identity, disposition and mastery through diverse practices." Rural Society: The Journal of Research into Rural and Regional Social Issues for Australia and New Zealand 15 (1): 4-21.

Billett, S. (1998). "Situation, Social systems and learning." Journal of Education and Work 11(3): 255-274.

Billett, S. (2001). "Learning through work: Workplace affordances and individual engagement." Journal of Workplace Learning 13(5): 209-214.

Billett, S. (2004). "From your business to our business: Industry and vocational education in Australia." Oxford Review of Education 30(1): 12-33.

Billett, S. (2005). Recognition of learning through work. International Handbook of Educational Policy. N. Bascia, Alister Cumming, A. Datnow, K. Leithwood and D. Livingstone. Dordrecht, The Netherlands, Springer. 2: 943-962.

Billett, S. (2009). "Conceptualising learning experiences: Contributions and mediations of the social, personal and brute." Mind, Culture and Activity 16(1): 32-47.

Billett, S., R. Smith, et al. (2005). "Understanding work, learning and the remaking of cultural practices." Studies in Continuing Education 27(3): 219-237.

Cavanagh, J. (2008). Women auxiliary workers' learning and discovering 'self' through work. Emerging Perspectives of Learning through work S. Billett, C. Harties and A. Eteläpelto. Rotterdam, The Netherlands, Sense Publishing: 67-82. 
Coopers and Lybrand (1995). Small business: a review of training evaluation and effectiveness' in Enterprising Nation (Research Report Volume 2), Canberra, AGPS., Industry Task Force on Leadership and Management Skills,.

Ericsson, K. A. and A. C. Lehmann (1996). "Expert and exceptional performance: Evidence of maximal adaptation to task constraints." Annual Review of Psychology 47: 273-305.

Erikson, E. H. (1959). Identity and the Life Cycle. . New York, International Universities Press.

Foucault, M. (1986). The care of the self: The history of sexuality, vol. 3. Harmondsworth, Penguin.

Giddens, A. (1991). Modernity and self-identity: Self and society in the late modern age. Stanford, Stanford University Press.

Glatthorn, A. (1987). Curriculum Leadership. Glenview, Illinois, Scott Foresham.

Gonon, P. (2009). The quest for modern vocational education: Georg Kerschensteiner between Dewey, Weber and Simmel. New York, Peter Lang.

Hodges, D. C. (1998). "Participation as dis-identification with/in a community of practice." Mind, Culture and Activity 5(4): 272-290.

Jackson, N. (1993). "If competence is the answer what is the question?' Vol.1, no.1, pp.46-60." Australian and New Zealand Journal of Vocational Education Research 1(1): 46-60.

Marsh, C. and G. Willis (1995). Curriculum: Alternative Approaches, Ongoing Issues. Englewod Cliffs, Merill.

Mealyea, R. (1985). "Working class students and the TAFE curriculum." Victorian TAFE papers: 27-36.

Organisation of Economic Cooperation and Development (2000). Economics and Finance of Lifelong Learning. Paris, OECD.

Pelissier, C. (1991). "The anthropology of teaching and learning." Annual Review of Anthropology 20: $75-95$.

Perkins, D., E. Jay, et al. (1993). "Beyond abilities: A dispositional theory of thinking." MerrillPalmer Quarterly 39(1): 1-21.

Raizen, S. A. (1989). Reforming education for work: A cognitive science perspective. Berkeley C A, National Centre for Research in Vocational Education.

Rogoff, B. (1990). Apprenticeship in thinking - cognitive development in social context. New York, Oxford University Press.

Rogoff, B. (1995). Observing sociocultural activity on three planes: Participatory appropriation, guided participation, apprenticeship. Sociocultural studies of mind. J. W. Wertsch, A. Alvarez and P. del Rio. Cambridge, UK, Cambridge University Press: 139-164.

Rohrkemper, M. M. (1989). Self-regulated learning and academic achievement: a Vygotskian view. Theory, research and practice: Progress in cognitive development research. B. J. Zinnerman and D. H. Schunk. New York, Springer-Verlag: 143-168.

Scribner, S. (1984). Studying working intelligence. Everyday cognition: Its development in social context. B. Rogoff and J. Lave. Cambridge, Mass, Harvard University Press: 9-40.

Scribner, S. (1985). Vygostky's use of history. Culture, communication and cognition: Vygotskian perspectives. J. V. Wertsch. Cambridge, UK, Cambridge University Press: 119-145.

Scribner, S. (1990). "Reflections on models." The Quarterly Newsletter of the Laboratory of Comparative Human Cognition 12(2): 90-94.

Searle, J. R. (1995). The construction of social reality. London, Penguin.

Skilbeck, M. (1984). School based curriculum development. London, Harper and Row.

Stenhouse, L. (1975). An introduction to curriculum research and development. London, Heinemann.

Stevenson, J. C. (1992). Contradictions, Complications and Competencies: Who cares? . Student services - Bridge to success - a TAFE national conference on student services. , Brisbane, Queensland.

Taylor, C. (1985). Human agency and language: Philosophical papers 1. Cambridge, Cambridge University Press. 
Tobias, S. (1994). "Interest, prior knowledge, and learning." Review of Educational Research 64(1): 37-54. 